\title{
The synthesis of magnetic nanoparticles from naturaliron sand of Kata beach Pariaman West Sumatera using ball milling method as environmental material
}

\author{
Erwin Amiruddin ${ }^{1 *}$ and Adhy Prayitno ${ }^{2}$ \\ ${ }^{1}$ Department of Physics, Universitas Riau, Pekanbaru, Indonesia \\ ${ }^{2}$ Department of Mechanical Engineering, Universitas Riau, Pekanbaru, Indonesia
}

\begin{abstract}
Synthesis, magnetic, and structural properties and adsorption study of magnetic particles of $\mathrm{Fe}_{3} \mathrm{O}_{4}$ have been carried out. Magnetic particles were synthesized from natural iron sand of Kata Beach Pariaman West Sumatera using ball milling method. The structural properties of the samples were determined using X-Ray Diffractometer (XRD) technique. Magnetic properties such as magnetization were measured based on hysteresis loop using vibrating sample magnetometer (VSM). Mass susceptibility of the sample was measured using Pasco magnetic probe. It was found that the mass susceptibility of magnetic particles increased significantly as ball milling time increased. Based on VSM results, the magnetic particle of $\mathrm{Fe}_{3} \mathrm{O}_{4}$ has magnetization value of $32.26 \mathrm{emu} / \mathrm{g}$ with small coercivity of 174 Oe. Moreover, the results showed that ball milling method has succeeded to obtain magnetic particles. The increase of ball milling time resulted in an increase of magnetic moment of the sample. In this research, the magnetic particle of $\mathrm{Fe}_{3} \mathrm{O}_{4}$ was added to a solution of methyline blue performed using shaker method. Atomic Adsorption Spectroscopy (AAS) method was used to study the methylene blue degradation.
\end{abstract}

\section{Introduction}

The synthesis of magnetic nanoparticles from iron sand has attracted great attention in the last years because of new physical and chemical properties of materials at the nanoscale. It is well known that this mineral consists of magnetite phase $\left(\mathrm{Fe}_{3} \mathrm{O}_{4}\right)$ and hematite $\left(\mathrm{Fe}_{2} \mathrm{O}_{3}\right)$, in nanometer size, the magnetite particles $\left(\mathrm{Fe}_{3} \mathrm{O}_{4}\right)$ posses an interesting property that is superparamagnetic. Therefore, research in nanoparticle magnetite is currently an area of intense scientific and technological interest. This is due to its magnetic properties that can be modified so that its applications become broader covering magnetic data storage [1, 2, 3, 4], magnetic sensor [5], separation of industrial pollutants from water [6], magnetic resonance imaging [7, 8], and drug delivery target [9, 10]. Magnetic nanoparticles are engineered particles in which its magnetic properties can be manipulated using an applied

*Corresponding author: erwin_amiruddin@yahoo.com 
magnetic field. Two crucial features, which are responsible for their novel magnetic properties, are finite-size effects and surface effects [11]. However, controlling of particles size of magnetite nanoparticle is an important parameter. Synthesis of magnetite nanoparticles with controllable size and constant distribution of particle size is a challenging problem especially in nanosize feature [12].

Synthesization of magnetic nanoparticles has been done by various methods such as chemical method [13] biological method [14] and physical method [15, 16]. One of the physical methods in synthesis of magnetic nanoparticles is ball milling method [17]. Ball milling method is a simple and efficient method in crunching the iron sand concentrate in a rotating tube using metallic or ceramic balls. In this method, ceramic balls that have higher mechanical energy are used to crunch the iron sand concentrate from the iron sand separator. The size of magnetic particles obtained through this method depends on the time, speed and weight of the ceramic balls [18]. Previous researchers [16, 17] have used this method to synthesize magnetic nanoparticles from the iron salt precursor. They found that the size of magnetic nanoparticles is around 10-15 nm. However, they also found that magnetic nanoparticles that synthesize using ball milling resulted in higher magnetic saturation (14 emu/gr) compared to that of using a chemical method that gives magnetic saturation value of $3 \mathrm{emu} / \mathrm{gr}$. In this article, we report the magnetic, structural properties of magnetic nanoparticles synthesized using ball milling method and state of the art uses of magnetic nanoparticles to study the methylene blue degradation.

\section{Experimental method}

Iron sand used in this research was collected from Kata Beach Pariaman West Sumatera. Before the synthesis process, the iron sand was dried under sun ray until it is completely dry. The iron sand was first synthesized using an iron sand separator, and then the product was synthesized using ball milling technique as a function of time. To separate between magnetic particles and nonmagnetic particles, then Neodymium iron boron magnet $(\mathrm{NdFeB})$ was employed. The magnetic properties especially magnetic susceptibility of particles powder was measured using Pasco magnetic probe. The structural properties of the magnetic powder were studied using X-Ray Diffractometer. Atomic Absorption Spectroscopy (AAS) method was used to analyze the methylene blue degradation. In this method, the selected magnetic particle of $\mathrm{Fe}_{3} \mathrm{O}_{4}$ was added as a function of weight to a solution of methylene blue performed using shaker method.

\section{Results and discussion}

Elemental composition of iron sand was determined using X-ray fluorescence (XRF). The composition before, and after crunching by ball milling is presented in Table 1 . Table 1 shows that the elemental composition was affected by processing time. It shows that the Fe content was increased very significantly after the ball milling process for 60 hours. However, some other elements, for example, $\mathrm{Si}, \mathrm{Al}, \mathrm{K}$, and $\mathrm{Ca}$ were decreased. This indicates that the ball milling process crunch the iron sand grains into smaller parts so that the nonmagnetic and magnetic grain were separated during the ball milling process. Mass susceptibility of the magnetic nanoparticles before and after ball milling procces is shown in Table 2. The data shown in Table 2 also can be presented in the form of graph in Fig. 1.

From Fig. 1 it can be seen that mass susceptibility of the magnetic nanoparticles increases as ball milling time increases. The value of mass susceptibility of the sample after being processed by ball milling is much higher than that of before being process by ball milling that is about $1654.700 \times 10^{-8} \mathrm{~m}^{3} / \mathrm{kg}$. The increase of mass susceptibility value of 
magnetic nanoparticles is due to the rise in the number of magnetic particles in the sample as confirmed by the result of XRF in Table 1 .

Table 1. Elemental composition of iron sand before and after ball milling process.

\begin{tabular}{|c|c|c|}
\hline \multirow{2}{*}{ Compound } & \multicolumn{2}{|c|}{ Concentration (\%) } \\
\cline { 2 - 3 } & Before ball milling & After ball milling 60 hours \\
\hline $\mathrm{Mg}$ & 3.531 & 3.46 \\
\hline $\mathrm{Al}$ & 11.06 & 8.3 \\
\hline $\mathrm{Si}$ & 62.261 & 17.156 \\
\hline $\mathrm{P}$ & 0.96 & 0.592 \\
\hline $\mathrm{Cl}$ & 2.15 & 0.583 \\
\hline $\mathrm{K}$ & 7.876 & 0.539 \\
\hline $\mathrm{Ca}$ & 5.941 & 1.272 \\
\hline $\mathrm{Ti}$ & 0.464 & 7.263 \\
\hline $\mathrm{V}$ & 0.006 & 0.398 \\
\hline $\mathrm{Mn}$ & 0.146 & 0.397 \\
\hline $\mathrm{Fe}$ & 4.086 & 57.335 \\
\hline $\mathrm{Others}$ & 1.519 & 1.786 \\
\hline
\end{tabular}

Tabel 2. Mass susceptibility of iron sand synthesized using ball milling method as a function of time.

\begin{tabular}{|c|c|c|c|c|}
\hline $\begin{array}{l}\text { Ball milling } \\
\text { time (hours) }\end{array}$ & $\begin{array}{l}\text { Volume } \\
\left(\mathbf{x} \mathbf{1 0}^{-6} \mathrm{~m}^{3}\right)\end{array}$ & $\begin{array}{c}\text { mass } \\
\left(\times 10^{-3} \mathrm{~kg}\right)\end{array}$ & $\begin{array}{c}\rho \\
\left(\mathrm{kg} / \mathrm{m}^{3}\right)\end{array}$ & $\begin{array}{c}\chi_{\text {massa }} \\
\left(\times 10^{-8} \mathrm{~m}^{3} / \mathbf{k g}\right)\end{array}$ \\
\hline 20 & 4 & 7,690 & 1922,500 & 3376,400 \\
\hline 40 & 7 & 12,500 & 1785,700 & 5729,710 \\
\hline 60 & 4 & 8,390 & 2097,500 & 7765,130 \\
\hline
\end{tabular}

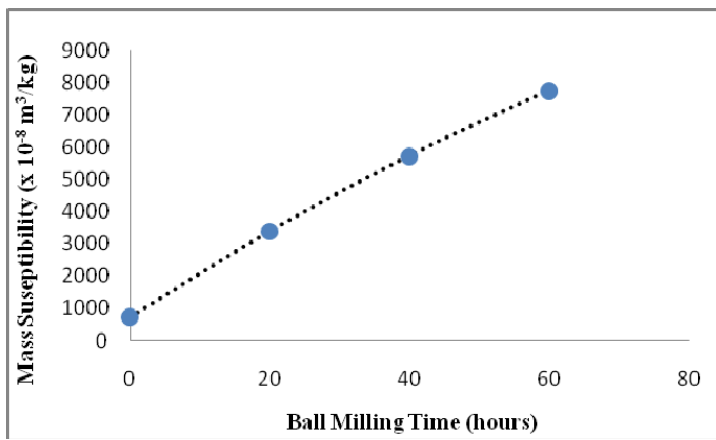

Fig. 1. Mass susceptibility of magnetic nanoparticles as a function of time. 
Crystal structure of magnetic nanoparticles $\left(\mathrm{Fe}_{3} \mathrm{O}_{4}\right)$ synthesized using ball milling was characterized using X-Ray Diffractometer Phillips that equipped with $\mathrm{Cu}$ tube producing $\mathrm{X}$ ray radiation with a wavelength of 1.5406 Angstroms. In this measurement, the diffraction angle was an interval of $10^{\circ}$ to $70^{\circ}$ with the step of $0.02^{\circ}$. X-ray diffraction pattern was obtained by applying a high voltage source that is around $40 \mathrm{kV}$ and $30 \mathrm{~mA}$. X-ray diffraction patterns of magnetic nanoparticles are shown in Fig. 3. From Fig. 3 it is clear that all diffraction peaks can be identified and its phase is faced center cubic (fcc). The availability of other compounds other than magnetite phase $\left(\mathrm{Fe}_{3} \mathrm{O}_{4}\right)$ could not be observed. The diffraction peaks of the magnetite phase are (2 20$)$, (3 11 1), (4 000$),\left(\begin{array}{lll}4 & 2 & 2\end{array}\right),\left(\begin{array}{lll}5 & 1 & 1\end{array}\right)$, and (4 00 0). From Fig. 3, it also can be found that although the crystal structure of magnetite does not change as a function of ball milling time, then the diffraction peaks become sharper and smaller for higher ball milling time namely 40 to 60 hours. This indicates that the crystalline state of the magnetite is increased as ball milling time increases.

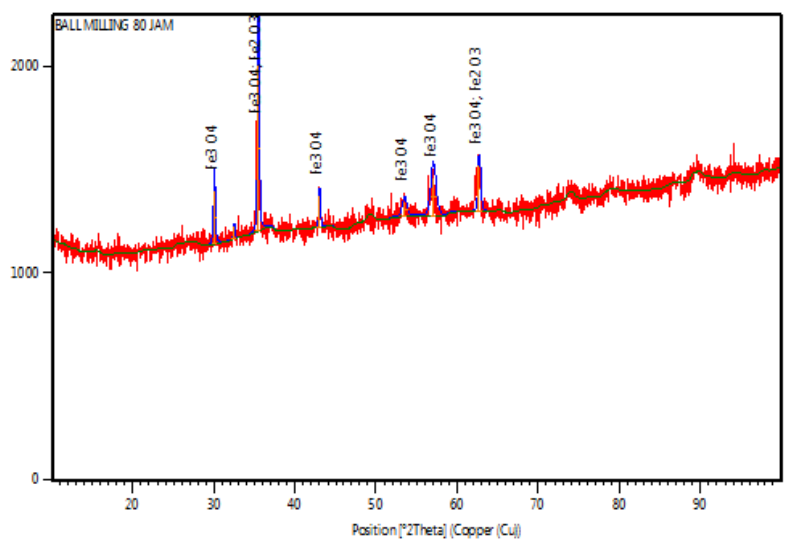

(a)

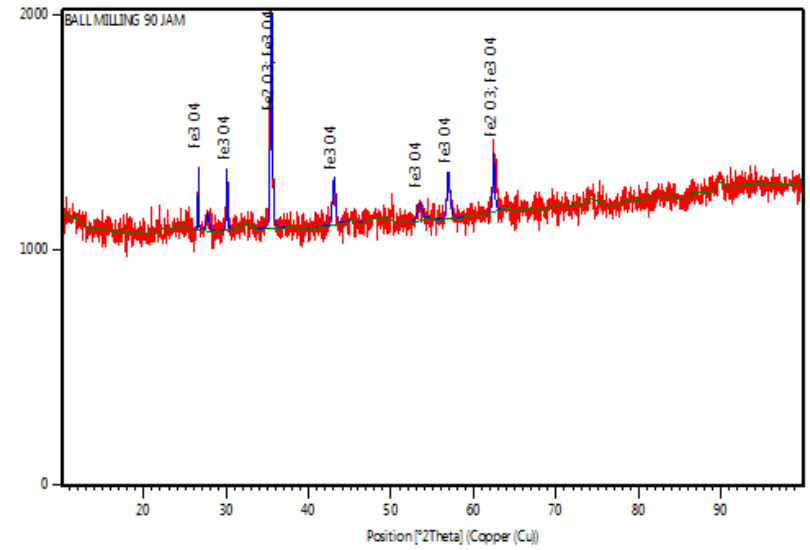

(b)

Fig. 2. X-Ray diffraction pattern of magnetic nanoparticles processed by ball millingor, (a) $40 \mathrm{hs}$, (b) 60 hours.

From Fig. 3 it also can be found that all diffraction peaks on the diffraction pattern show the peaks that is agree well with the standard structure of magnetite phase $\left(\mathrm{Fe}_{3} \mathrm{O}_{4}\right)$. The average size of magnetite crystal for 40 and 60 hours ball milling process are respectively $42.58 \mathrm{~nm}$ and $32.24 \mathrm{~nm}$. The average size of magnetite nanoparticles was calculated based on line-broadening of diffraction pattern using Scherrer formulation [19]. 


$$
d=\frac{0.9 \lambda}{\beta \cos \theta}
$$

where $d$ is dimension or size of crystal in (nm), $\theta$ is incident angle of $\mathrm{x}$-ray, $\lambda$ is x-ray wavelength $(0.15406 \mathrm{~nm}), \beta$ is FWHM (full wave half maximum). Crystal size of magnetite nanoparticles obtained in this research was calculated based on the highest reflection peak that is around $35.45^{\circ}$.

\section{Conclusions}

Magnetite nanoparticles $\mathrm{Fe}_{3} \mathrm{O}_{4}$ were successfully synthesized by a simple and cost-effective ball milling method as a function of time that is 40 and 60 hours. The XRF, XRD, and Pasco magnetic probe were used to characterize the composition, structure, and magnetic properties of the nanoparticles. The degree of crystallinity of magnetic nanoparticles increases when ball milling time increases, while the size of magnetic nanoparticles decreases as ball milling time increases. The results also reveal that the mass susceptibility of magnetic nanoparticles increases as ball milling time increases.

\section{References}

1. A. Srivastava, A. Ojha, S. Chaubey, J. Singh, P. Sharma, J. of Alloys and Compounds, $\mathbf{5 0 0}(2010)$

2. C.T. Black, C.B. Murray, R.L. Sandstrom, S. Sun, Science 290 (2000)

3. H. Zeng, J. Li, J.P. Liu, Z.L. Wang, S.H. Sun, Nature 420 (2002)

4. E. Amiruddin, A. Prayitno ARPN J. of Eng. and Appl. Sci. 12, 12 (2017)

5. Erwin, AIP Conf. Proc. 1801 (2017)

6. S. Asuha, Y.W. Gao, W. Deligeer, M. Yu, B. Suyala, S. Zhao. J. Por. Mat. 18, (2011)

7. S. Zhang, Y.Y. Qi, H. Yang, M.F. Gong, D. Zhang, L.G. Zou, J. of Nanoparticle Res. 15 (2013)

8. L.X. Tifenauer, A. Tschirky, G. Kuhne, R.Y. Andres, Magn. Reson.Imaging 14 (1996)

9. M. Mahmoudi, S. Sant, B. Wang, S. Laurent, T. Sen, Adv. Drug Deliv. Rev. 63, 1-2 (2011)

10. A. Lu, E. Hui, L. Salabas, F. Schüth, Angewandte Chemie Int. Edition 46, 8 (2007)

11. H.L. Ling, S. Pilko, J.H. Wu, M.H. Jung, J.H. Min, J.H. Lee, B.H. An, Y.K. Kim, J. Magn. Mater. 310 (2007)

12. A.B. Chin, I.I. Yaacob, J. Mat. Process Tech. 191 (2007)

13. M.R. Lisy, A. Hartung, C. Lang, D. Schuler, W. Richter, J.R. Reichenbach, W.A. Kaiser, I. Hilger, I. Invest Radiol. 42 (2007)

14. Z.M. Wang, Y. Liu, X.Y. Zeng, Powder Tech. 161 (2006)

15. L. Almásy, D. Creanga, C. Nadejde, L. Rosta, E. Pomjakushina, M. Ursache-Oprisan, J. of the Serbian Chem. Soc. 80, 3 (2015)

16. D.M. Silaban, Erwin, Yanuar, A. Prayitno, Proc. of the $3^{\text {rd }}$ Int. Conf. on Science, Technology and Interdisciplinary Research 2017 (2017)

17. G.F. Goya, Solid State Communications 130, 12 (2004)

18. M. Abareshi, E.K. Goharshadi, S.M. Zebarjad, F.H. Khandan, A. Yussefi, J. Magn. Mater. 322 (2010) 